\title{
Scanning Electron Microscopy Studies of Root Canal Dentin Irrigated with a Chitosan-Citrate Solution: A Preliminary Report
}

\author{
Gusiyska $A^{1}$, Vassileva $R^{2}$, Dyulgerova $E^{3}$, Ilieva $R^{4}$, Mironova $\mathbf{J}^{5}$, Gyulbenkiyan $E^{6}$ \\ 1,2,3,5, ${ }^{6}$ Department of Conservative Dentistry, Faculty of Dental Medicine, Medical University - Sofia, Bulgaria \\ ${ }^{4}$ Institute of General and Inorganic Chemistry, Bulgarian Academy of Sciences - Sofia, Bulgaria
}

\begin{abstract}
The success of endodontic treatment depends on thorough cleaning and shaping of the root canal system. In recent years, attention has focused on the role of chitosan instead of ethylenediaminetetraacetic acid (EDTA) as a complexing agent in root canal irrigation. In this in vitro study, dentin samples from the root canal were irrigated with varying concentrations of a chitosan-citrate solution. All the samples were analysed using scanning electron microscopy (SEM), and the smear layer covering the dental surfaces at the coronal, middle and apical root canal levels was evaluated. The results demonstrated that a $0.6 \%$ solution of chitosan in $1 \%$ citric acid was very effective at removing the smear layer.
\end{abstract}

Keywords: EDTA, chitosan, citric acid, root canal irrigation, smear layer

\section{Introduction}

The elimination of the bacterial biofilm from the root canal system is a focal point in the management of endodontic diseases. The effectiveness of root canal instrumentation and irrigation underpins the success of modern endodontic treatment. Modern methods of instrumentation use nickeltitanium files, which produce a layer of organic and inorganic material called a smear layer. The smear layer consists of pulp tissue, remnants of odontoblastic processes, bacteria and their by-products, which impedes the disinfection of the canal [3]. By obstructing the dentinal tubules, the smear layer prevents the penetration of intracanal medicaments and root filling materials from adhering to the canal walls. Even with current techniques using nickel-titanium files, more than $35 \%$ of the root canal's surface can be left uninstrumented [18]. Copious irrigation is required to remove debris and reduce microorganisms in the complex root canal system. The ultimate irrigating solution should eliminate both organic and inorganic phases of the smear layer and not have an erosive effect on dentin surfaces [24, 25]. Shahravan et al. (2007) concluded that the removal of the smear layer reduced apical leakage [20]. Although sodium hypochlorite $(\mathrm{NaOCl})$ is considered the gold standard irrigant solution, there is no solution at present capable of acting simultaneously on the organic and inorganic elements of the smear layer [2]. $\mathrm{NaOCl}$ at a concentration of $1-5.25 \%$ is most commonly used because of its bactericidal effectiveness and ability to dissolve organic tissue [26]. However, $\mathrm{NaOCl}$ was reported to exhibit cytotoxicity when injected into periradicular tissue [6]. It was also reported to have an unpleasant taste, in addition to potential for caustic corrosion and allergic reactions [6]. Research also demonstrated that it had no effect on the inorganic part of the smear layer [5].

Ethylenediaminetetra acetic acid (EDTA) is biocompatible irrigant with a $\mathrm{pH}$ of 7 and no antibacterial effect. EDTA is used at concentrations of $15-17 \%$ to eliminate calcium from dentin, leaving an organic substance, which has no toxic effect on periapical tissue. A previous study reported the use of a dual irrigation regime of $\mathrm{NaOCl}$ and EDTA to remove debris and the smear layer in enlarged, narrow or obstructed root canals [1]. However, this dual irrigation regime still had erosive activity [14]. The elimination of the bacterial biofilm from the root canal system remains the main goal in the management of endodontic diseases. However, microbial communities in biofilms are remarkably difficult to eliminate, as microorganisms in mature biofilm can be resistant to irrigants [23]. Current methods to remove biofilms include chemical, ultrasonic and laser techniques [23]. None of these methods have been shown to be particularly effective, and none have been universally accepted [23].

Citric acid, an organic acid, is used at concentrations ranging from $1-50 \%$ to remove the inorganic portion of the smear layer [17]. A $10 \%$ solution is the most common and is used for 2-3 min at the end of instrumentation and after $\mathrm{NaOCl}$ irrigation [7]. As an irrigant to remove the smear layer, citric acid has been reported to have low cytotoxicity, good chelating properties and good antimicrobial properties. The antibacterial effectiveness of citric acid is directly proportional to its concentration [22]. A concentration of $10 \%$ citric acid ( $\mathrm{pH} 1.8)$ was reported to be ideal for the chelation of calcium and phosphorous ions in dentin [10]. Although a high concentration of citric acid (50\%) removed the smear layer, it also caused dentin erosion $[1,3,7]$. Therefore, citric acid cannot exert both antibacterial and chelating effects simultaneously. Citric acid formulations containing antibiotics have been studied, but these tended to produce bacteria resistant to antibiotics $[2,8]$.

Chitosan is a natural polysaccharide obtained by the deacetylation of chitin, which is found in crab and shrimp shells [13]. It has attracted a great deal of attention in dental research because of its biocompatibility, biodegradability, bioadhesion and lack of toxicity [21]. Due to its high chelating ability for various metal ions in acidic conditions, 


\section{International Journal of Science and Research (IJSR) \\ ISSN (Online): 2319-7064 \\ Index Copernicus Value (2013): 6.14 | Impact Factor (2014): 5.611}

it has been applied widely in the removal or recovery of metal ions in different industrial areas [13]. The structure of chitosan is similar to that of extracellular matrix proteins, such as proteoglycans and glycosaminoglycan. Previous research demonstrated its ability to enhance the mechanical properties of dentin collagen and to reinforce collagen constructs [8]. Studies also showed that chitosan nanoparticles and their derivatives interacted with and neutralised matrix metalloproteinases (MMPs) or bacterial collagenase and improved the resistance of dentin to degradation $[12,15]$.

Various studies have reported different findings on the effectiveness of contemporary irrigant solutions to remove the smear layer and debris. Most studies reported that these irrigating solutions were ineffective, especially in the apical third $[4,5,6]$. Due to the limitations of current endodontic irrigants, there is great interest in developing new, improved irrigating solutions.

Based on the current literature, we hypothesised that a mixed chitosan-citrate solution would effectively and safely remove the smear layer. Thus, this in vitro study evaluated the degree of smear layer removal dentin and the opening of the dentin tubules following the application of different concentrations of a chitosan-citrate solution. Scanning electron microscopy (SEM) was used to evaluate the smear layer removal from the coronal, middle and apical thirds of canals treated with the chitosan-citrate solution and the opening of dentin tubules.

\section{Materials and Methods}

Twelve freshly extracted single-rooted human teeth were used in this study. All the teeth were placed in a $2.5 \%$ $\mathrm{NaOCl}$ solution for $15 \mathrm{~min}$. The tissue and debris remnants on the root surface were then removed and stored in a $0.9 \%$ saline solution. Each tooth was decoronated, and the root length was standardised to $16 \mathrm{~mm}$ for canal instrumentation. All the endodontic treatments were performed according to current protocols for endodontic procedures. The canals were enlarged with rotary nickel-titanium instruments (ProTaper Universal, Dentsply Maillefer), using the crowndown technique. The citrate-chitosan solutions were prepared in different concentrations, ranging from $0.1-0.6 \%$, with $0.1-0.6 \mathrm{mg}$ of the chitosan powder dissolved in $100 \mathrm{ml}$ of $1 \%$ citric acid. Using the chitosan-citrate solution, continuous irrigation was applied for $5 \mathrm{~min}$ to remove the smear layer, taking care to avoid erosion of the dentin. Finally, the root canals were rinsed with $5 \mathrm{ml}$ of a $0.9 \%$ saline solution. The radicular part of each tooth was gently split longitudinally into two halves: vestibular and lingual (palatinal). The obtained specimens were desiccated, vacuum-coated with gold dust in an argon medium with cathode sputtering (JEOL JFC-1200 Fine Coater, Tokyo, Japan) and examined using a scanning electron microscope (JEOL JSM-5510, Tokyo, Japan) at $\times 2500,5000$ and 10,000 magnification.

\section{Results}

The chitosan-based irrigant solution had different effects on the surfaces of the dentin and on the opening of the dentin tubule, depending on the concentration of the solution
(Figs.1-4). The chitosan-based irrigant solution also had conditioning effect on the inter- and intra-tubular spaces. The chitosan solution also reinforced the collagen (Figs. 5, $6)$.

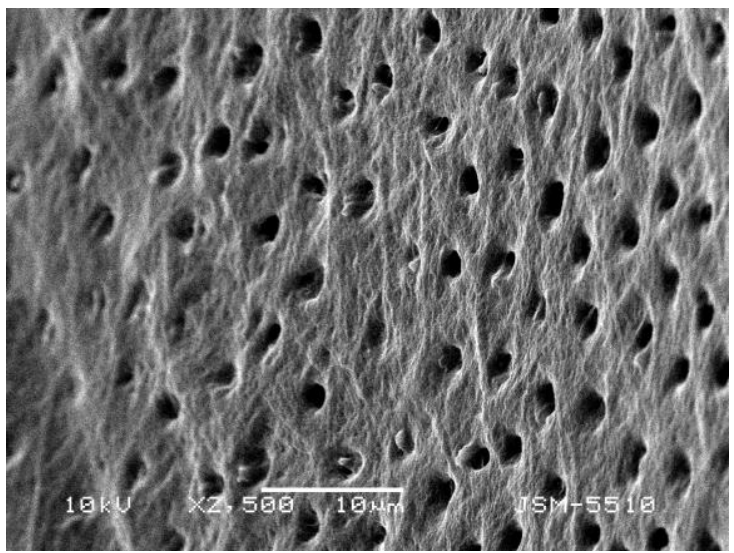

Figure 1: SEM of prepared radicular dentin irrigated with the $0.1 \%$ chitosan solution (magnification $\times 2500$ ).

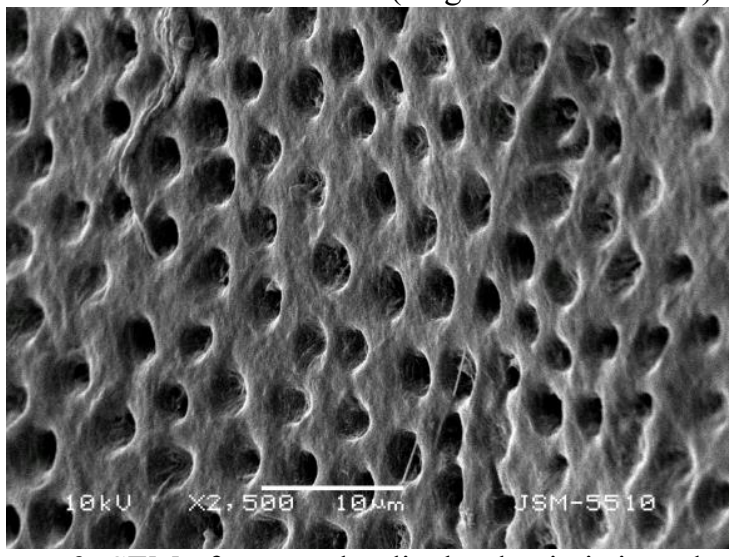

Figure 2: SEM of prepared radicular dentin irrigated with the $0.6 \%$ chitosan solution (magnification $\times 2500$ )

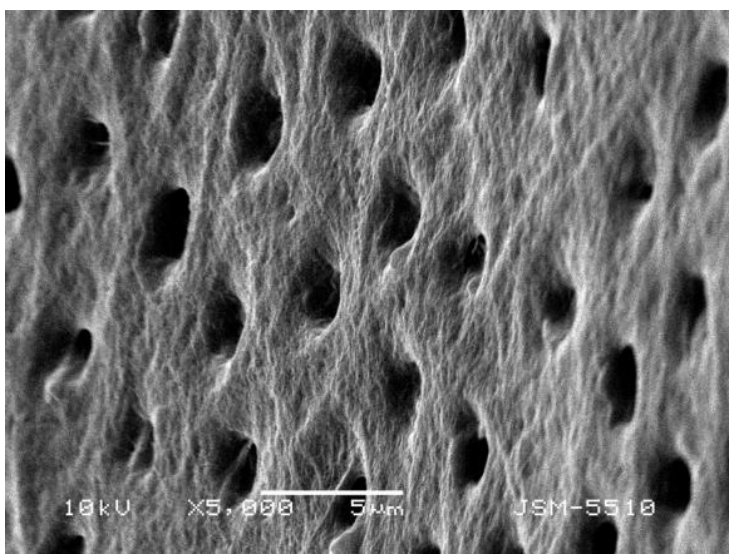

Figure 3: SEM of prepared radicular dentin irrigated with the $0.1 \%$ chitosan solution (magnification $\times 5000$ )

\section{Discussion}

Thorough debridement of the root canal system is essential in endodontic treatment, and irrigation solutions are the main way of removing the smear layer produced. 


\section{International Journal of Science and Research (IJSR) \\ ISSN (Online): 2319-7064}

Index Copernicus Value (2013): 6.14 | Impact Factor (2014): 5.611

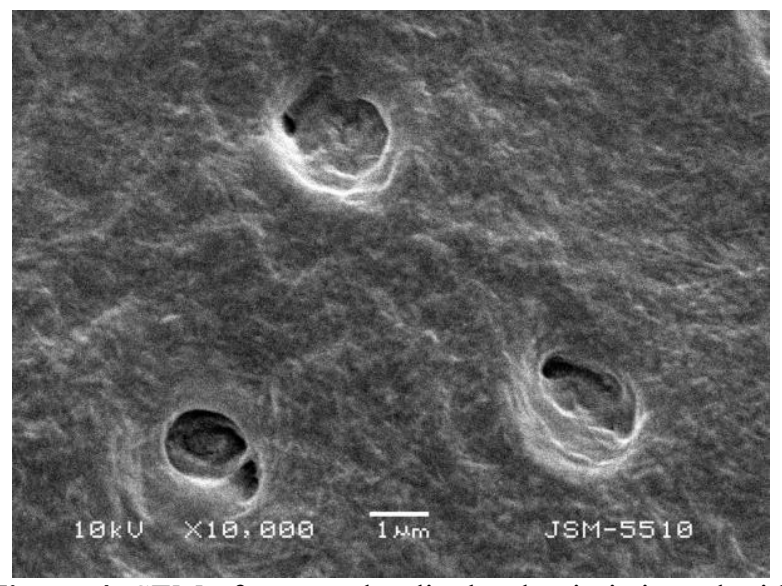

Figure 4: SEM of prepared radicular dentin irrigated with the $0.1 \%$ chitosan dentin solution (magnification $\times 10000$ ).

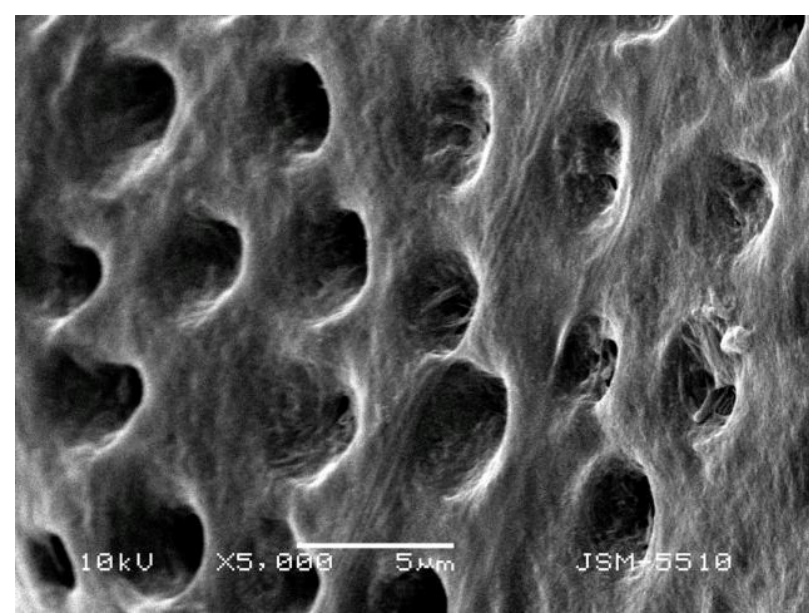

Figure 5: SEM of prepared radicular dentin irrigated with the $0.6 \%$ chitosan solution (magnification $\times 5000$ )

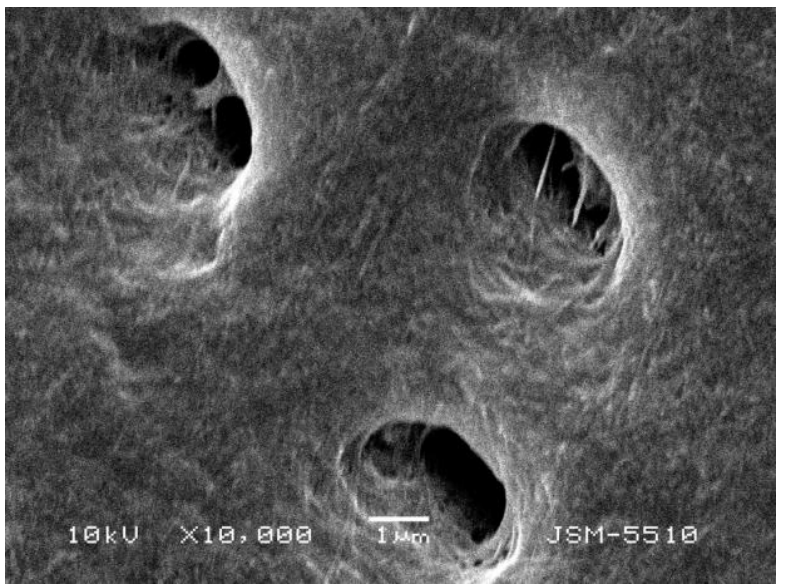

Figure 6: SEM of prepared radicular dentin irrigated with the $0.6 \%$ chitosan solution (magnification $\times 10000$ )

during this treatment [7,24]. At present, there are no irrigating solutions capable of removing both the organic and inorganic elements of the smear layer [2]. It is well known that the efficiency of a chelating agent depends on several factors, such as the $\mathrm{pH}$, application time and the amount and concentration of the irrigant solution [11]. Calcium and phosphorous, which are the main inorganic elements of dentin, are present in hydroxyapatite crystals in a ratio of 2:1. Any changes in this ratio can damage the proportion of inorganic components and increase the permeability of radicular dentin $[9,16]$

The effect of the $0.1 \%$ and $0.6 \%$ chitosan solutions used in this study on smear layer removal in the coronal, middle and apical thirds of the samples was satisfactory. According to the results of a previous study, the application of a $0.2 \%$ chitosan solution for 3-5 min was the most appropriate combination for removing the smear layer [19]. The hydrophilic nature of chitosan, which contains a large number of free hydroxyl and amino groups, facilitated ionic interactions with dentin calcium ions [27].

Within the limitations of this preliminary study, it can be concluded that the cleaning of the dentin tubules was best using the $0.6 \%$ chitosan solution. The $0.1 \%$ chitosan solution removed the smear layer but did not completely open the dentin tubules.

\section{Conclusion}

Under the conditions of this study, the chitosan-based irrigant solution (at a concentration of $0.6 \%$ ) showed a satisfactory ability to remove the smear layer and open the dentin tubules for subsequent sealing of the root canal system. Future studies should focus on determining the most appropriate concentration for maximum elimination of the smear layer and investigating the physical, chemical and biological properties of chitosan solutions to preserve dentin and prevent erosion.

\section{Acknowledgements}

This work was financially supported by the Bulgarian Ministry of Education and Science under Project DFNI T02$5 / 2014$.

\section{References}

[1] Balaji T. Effect of various root canal irrigants on removal of smear layer and debris - an SEM Study. Pakistan Oral Dental J 2010; 30: 205-11.

[2] Barkhordar R, Watanabe L, Marshall G, Hussain M. Removal of intracanal smear by doxycycline in vitro. Oral Surg Oral Med Oral Pathol 1997; 84 (4): 420-3.

[3] Berutti E, Marini R, Angeretti A. Penetration ability of different irrigants into dentinal tubules. J Endod 1997; 23 (12): 725-7.

[4] Felippe M, Moresco C, Stolf S, Felippe W. Removal of intracanal smear layer by doxycycline: SEM analysis. Aust Endod J 2010; 36: 64-9.

[5] Gernhardt C, Eppendorf K, Kozlowski A, Brandt M. Toxicity of concentrated sodium hypochlorite used as an endodontic irrigant. Int Endod J 2004; 37: 272-80.

[6] Gomes B, Ferraz C, Vianna M, Berber V, Teixeira F, et al. In vitro antimicrobial activity of several concentrations of sodium hypochlorite and chlorhexidine gluconate in the elimination of Enterococcus faecalis. Int Endod J 2001; 34: 424-428.

[7] Haapasolo M, Shen Y, Qian W, Gao Y. Irrigation in endodontics. Dent Clin North Am 2010; 54: 291-312. 


\section{International Journal of Science and Research (IJSR) \\ ISSN (Online): 2319-7064}

Index Copernicus Value (2013): 6.14 | Impact Factor (2014): 5.611

[8] Haznedaroglu F. Efficacy of various concentrations of citric acid at different $\mathrm{pH}$ values for smear layer removal. Oral Surg Oral Pathol Oral Radiol Endod 2003; 96: 340-344.

[9] Hennequin M, Douillard Y. Effects of citric acid treatment on the $\mathrm{Ca}, \mathrm{P}$ and $\mathrm{Mg}$ contents of human dental roots. J Clin Periodontol 1995; 22: 550-7.

[10]Hennequin M, Pajol J, Avignant D. Effect of different $\mathrm{pH}$ values of citric acid on calcium and phophorus contents of human root dentin. J Endod 1994; 20: 551554.

[11]Hülsmann M, Heckendorff M, Lennon A. Chelating agents in root canal treatment: mode of action and indications for their use. Int Endod J 2003; 36: 810-30.

[12] Kim M, Kim S. Chitooligosaccharides inhibit activation and expression of matrix metalloproteinase - 2 in human dermal fibroblasts. FEBS Lett 2006; 580: 2661-6.

[13] Kurita K. Chemistry and application of chitin and chitosan. Polymer Degradation and stability 1998; 59: 117-20.

[14] Mancini M, Armellin E, Casaglia A, Cerroni L, Cianconi L. A comparative study of smear layer removal and erosion in apical intraradicular dentine with three irrigating solutions: a scanning electron microscopy evaluation. J Endod 2009; 35: 900-3.

[15] Pashley D, Tay F, Yiu C, Hashimoto M, Breschi L, Carvalho $\mathrm{R}$, et al. Collagen degradation by host derived enzymes during aging. J Dent Res 2004; 83: 216-21.

[16] Perez V, Cardenas M, Planells U. The possible role of $\mathrm{pH}$ changes during EDTA demineralization of teeth. Oral Surg Oral Med Oral Pathol 1989; 68: 220-2.

[17] Pérez-Heredia M, Ferrer-Luque C, Rodrn G, Guez M. The effectivness of different acid irrigating solutions in root canalcleaning after hand and rotary instrumentation. J Endod 2006; 32: 993-7.

[18] Peters O. Current challenges and concepts in the preparation of root canal systems: a review. J Endod 2004; 30: 559-567.

[19] Pimenta J, Zaparolli D, Pecora J, Cruz-Filho A. Chitosan: effect of a new chelating agent on the microhardness of root dentin. Braz Dent J 2012; 23: 212-7.

[20] Shahravan A, Haghdoost AA, Adl A, Rahimi H, Shadifar F. Effect of smear layer on sealing ability of canal obturation: a systematic review and meta-analysis. J Endod. 2007; 33(2): 96-105.

[21] Silva P, Guedes D, Nakadi F, Pecora J, Cruz-Filho A. Chitosan: a new solution for removal of smear layer after root canal instrumentation. Int Endod 2013; 46: 332-338.

[22] Smith J, Wayman B. An evaluation of the antimicrobal effectiveness of citric acid as a root canal irrigant. J Endod 1986; 12: 54-58.

[23] Torabinjad M, Cho Y, Khademi A, Bakland L, Shabahang S. The effect of various concentrations of sodium hypochlorite on the ability of MTAD to remove the smear layer. J Endod 2003; 29: 1001-9.

[24] Torabinejad M, Handysides R, Khademi A, Bakland L. Clinical implicationsof the smear layer in endodontics: a review. Oral Surg Med Oral Pathol Oral Radiol Endod 2002: 94 (6): 658-66.
[25] Torabinejad M, Khademi A, Babagoli J. A new solution for the removalof the smear layer. J Endod 2003; 29 (3): 170-5.

[26] Yamada R, Armas A, Goldman M, Lin P. A scanning electron microscopic comparison of a high volume final flush with several irrigating solutions: part 3. J Endod 1983; 9(4): 137-42.

[27]Zhang J, Xia Z, Liu P, Cheng Q, Tahirou T, Gu W, et al. Chitosan modification and pharmaceutical/ biomedical applications. Mar Drugs 2010; 8: 1962-87. 